\title{
DINAMIKA PSIKOLOGIS PELAKU SELF-INJURY (STUDI KASUS PADA WANITA DEWASA AWAL)
}

\author{
Ria Kurniawaty \\ Psikologi. Fakultas Ilmu Pendidikan. Universitas Negeri Jakarta \\ Jl. Rawamangun Muka, Jakarta Timur \\ Email : kurniawaty.inhere@gmail.com
}

\begin{abstract}
This study aimed to gain insight about the dynamics of self-Injury actors. The approach used in this research is a qualitative approach with case study method. Subjects in this study is that two actors Injury non suicidal self-injury self-moderate. Data collection techniques used were observation and interviews. Data analysis using qualitative data analysis techniques and examination techniques data using triangulation. Triangulation is used in this study is the triangulation of methods and sources. This study shows that the psychological dynamics of self-Injury actors in subject 1 came from the family, parenting adopted in the family persuasive. The role of each member of the family is not running as it should. Circumstances are not good parents is what makes the subject to self-injury. Lack of attention and affection from parents makes the subject perform actions that are not controlled by it as self-injury. Subject 2 showed that the role of the family is quite influential for him. Parenting is applied by the subject's father was so protective that makes the subject very often want to feel free. This event makes the subject feel guilty and depressed. Taste is exactly what makes the subject matter that is not doing well coping with self-injury.
\end{abstract}

Keywords: Self-Injury, Psychological Dynamics.

\section{Pendahuluan}

Wanita adalah sosok tangguh dan juga sering dikatakan lemah dibandingkan pria. Wanita di balik sosok lembutnya menyimpan banyak pesona yang luar biasa dalam dirinya namun, karena sifat wanita yang lembut dan dikatakan lemah inilah yang sering membuat wanita direndahkan dan dilecehkan secara psikis oleh orang-orang disekitarnya. Sehingga banyak dari para wanita khususnya mempunyai masalah psikis yang cukup berat, seperti stress terhadap keluarga maupun stress 
terhadap masalah-masalah di lingkungan sekitarnya. Hal ini sering sekali membuat wanita memendam masalahnya dan meluapkan masalahnya dengan cara yang tidak baik. Cara-cara inilah yang terkadang membuat khawatir dirinya dan lingkungan sekitarnya.

Hubungan seorang anak dengan

keluarganya merupakan bentuk sosialisasi pertama anak tersebut, karena lingkungan awal terbatas pada rumah, maka hubungan antar keluarga mempunyai peran yang penting dalam menentukan sikap dan perilaku seorang anak itu kelak dan hubungannya dengan orang lain. Meskipun pola ini akan berubah dengan semakin besarnya anak tersebut dan luasnya hubungan lingkungan yang akan dijalaninya, tetapi pola inti cenderung dimulai dari keluarga dan ini bersifat tetap. Inilah mengapa hubungan keluarga merupakan unsur yang sangat penting bagi perkembangan seseorang baik secara fisik maupun emosional (Hurlock, 1980).

Perkembangan emosional pada masa kanak-kanak sampai remaja sangatlah penting perannya bagi perjalanan emosinya. Bahaya awal emosional seorang anak adalah dominasi emosi yang kurang baik, terutama amarah. Seorang anak yang mengalami emosi negatif yang terlalu banyak dan hanya sedikit mengalami emosi-emosi yang menyenangkan maka hal ini akan mengganggu pandangan hidup dan mendorong perkembangan watak yang tidak baik. Perkembangan emosional dapat di dukung dari interaksi sosialnya.

Lebih lanjut menurut Hurlock (1980) masa remaja adalah masa perubahan dari masa anak-anak menuju masa dewasa dan masa dewasa adalah puncak kematangan seseorang dalam hidupnya. Dalam menjalani masa transisi ini pasti akan ada konflik yang terjadi, konflik internal (konflik dalam dirinya) maupun konflik eksternal (konflik yang berasal dari luar). Konflik internal misalnya perasaan malu, perasaan yang mendalam atau putus asa. Sedangkan konflik eksternal misalnya pertengkaran hebat dengan orang yang dicintai, tidak diterima di lingkungan sosialnya, atau bahkan mendapatkan perlakuan yang tidak baik dar temantemannya. Konflik-konflik ini menyebabkan seseorang menjadi tertekan secara emosional menimbulkan perasaan yang tidak nyaman pada dirinya (Walsh, 2006).
Usia-usia remaja dan dewasa awal seorang akan menemukan banyak konflik yang terjadi kepadanya. Cara penyelesaian konflik atau coping yang ia lakukan merupakan salah satu gambaran dari bentuk penerapan atau cara yang biasa ia lakukan sedari masa kecilnya. Ada mekanisme coping yang dilakukan dengan baik dan ada mekanisme coping yang dilakukan dengan baik dari seorang individu itu sendiri. Mekanisme coping yang baik di lakukan dengan cara-cara yang positif misalnya menyelesaikan masalah dengan baik kepada individu yang bersangkutan, mengolah perasaannya sehingga terbentuk regulasi emosi yang baik dan mengarah. Sehingga dapat membantu individu itu untuk dapat menyelesaikan masalahnya dengan baik namun, lain halnya bagi seseorang yang tidak dapat melakukan penyelesaian masalahnya dengan baik. Banyak hal yang dilakukannya menjadi tidak baik bagi dirinya maupun bagi orang-orang yang berada di luar lingkungannya. Mereka yang seperti itu cenderung melakukan aksi penyelesaian masalahnya seperti dengan memendam rasa emosinya, dan tidak menyalurkannya. Hal ini juga terpengaruh dari pembentukan pribadi seseorang dan pola dari lingkungannya, (Hurlock, 1980).

Tidak semua orang dapat mengolah perasaan ini. Perasaan distress yang ditimbulkan akibat tekanan yang dialami dari dalam dan luar dirinya. Selain itu masalah ini bisa juga disebabkan oleh daya tahan terhadap distresnya yang rendah dan tidak terkontrol. Ada sebagian orang yang melampiaskan distresnya dengan cara yang negatif dan berdampak buruk bagi dirinya dan lingkungan disekitarnya. Seperti misalnya menyakiti dirinya sendiri dengan cakaran-cakaran yang dibuat sendiri, melukai tubuhnya secara sengaja sehingga mengkhawatirkan banyak orang-orang di sekitarnya. Perilaku menyakiti atau melukai dirinya sendiri di sebut sebagai perilaku Self-Injury.

Self-Injury (Klonsky \& Jenifer, 2007) adalah prilaku dimana seseorang sengaja melukai tubuhnya sendiri bukan bertujuan untuk bunuh diri melainkan hanya untuk melampiaskan emosiemosi yang menyakitkan. Banyak yang melakukannya karena mekanisme ini bekerja dan bahkan dapat menyebabkan kecanduan, selfInjury hanya menyebabkan pembebasan yang 
bersifat sementara dan tidak mengatasi akar permasalahan sehingga seseorang yang pernah melakukannya akan memiliki kecenderungan untuk mengulanginya dengan peningkatan frekuensi.

Pelaku menyakiti diri mereka sendiri (self-injury) dalam upaya mengurangi masalah emosionalnya karena bagi para pelaku lebih baik sakit fisik dari pada sakit psikis atau sakit secara emosionalnya. Pelaku self-Injury melakukan tindakan menyakiti diri sendiri secara sengaja karena maksud untuk mengurangi ketegangan dan merasa lebih tenang yang ia rasakan dari perasaan yang tidak nyaman yang diperoleh dari rasa penolakan yang ia rasakan. Perasaan tenang tersebut hanya bersifat sementara karena pada dasarnya tindakan ini tidak menyelesaikan permasalahan yang sebenarnya terjadi pada dirinya (Hit \& Cha, 2006). Self-Injury merupakan mekanisme coping yang digunakan seseorang secara individu untuk mengatasi rasa sakitnya secara emosional atau menghilangkan rasa kekosongan secara kronis dalam diri dengan memberikan sensasi pada diri sendiri, self-Injury sendiri merupakan mekanisme coping yang tidak baik namun banyak orang yang melakukan karena memang mekanisme tersebut menjadi cara yang efektif bekerja dan bahkan bisa menyebabkan kecanduan (Alderman, 1997).

Beberapa orang mungkin pergi ketempat beladiri atau atau tempat hiburan untuk berolahraga atau untuk melampiaskan kemarahan mereka. Beberapa orang mungkin melakukan jogging, berenang atau yoga, untuk alasan kesehatan dan juga untuk mendapatkan sensasi kebahagiaan secara fisik atau emosional. Hal itu semua tidak dapat dilakukan sepenuhnya oleh para pelaku self-Injury karena mereka mengalami hambatan baik secara psikis maupun fisik dalam mengungkapkan kemarahan mereka; Fieldman (2000); dalam Mounty, (2005) berpendapat bahwa. kemungkinan perilaku self-Injury yang tinggi adalah pada korban kekerasan, dan individu anti sosial, dalam sebuat situasi dimana mereka mengalami hambatan baik secara fisik maupun psikis dan mengungkapkan kemarahan mereka. Hambatan yang terjadi adalah rasa rendah diri dan menarik diri dari lingkungannya karena merasa malu dan merasa tidak di terima di lingkungannya.

Banyak orang yang mengira bahwa selfInjury dilakukan untuk mencari perhatian namun, dalam kenyataannya banyak pelaku yang menyadari keberadaan luka pada tubuh mereka dan berusaha menyembunyikannya dengan memakai baju lengan panjang. Jika orang lain menanyakan bagaimana mereka memperoleh luka tersebut, mereka akan menjawab dengan cara lain misalnya jatuh atau mengalami kecelakaan. SelfInjury dipercaya untuk meregulasi emosi dengan merasakan rasa sakit. Lebih mudah untuk menghadapi rasa sakit fisik daripada rasa sakit emosional. Untuk beberapa orang, cara satusatunya untuk melepaskan tekanan adalah dengan self-Injury. Prilaku ini cenderung muncul setelah mengalami pengalaman yang menyedihkan dan muncul saat seseorang tidak mengetahui cara untuk mengekspresikan perasaan dengan cara yang lebih sehat. Mereka berpikir jika mereka merasakan rasa sakit secara eksternal dimana lukanya terlihat maka mungkin akan ada kemungkinan untuk sembuh. Mereka juga percaya bahwa luka akan membuktikan bahwa rasa sakit emosional mereka nyata.

Sebagian besar pelaku self-injury mengatakan bahwa self-injury terjadi begitu saja, namun hal tersebut juga dapat berkembang melakui proses observasi dengan memperhatiakan dan mencontoh apa yang dilakukan oleh orang lain. Mereka yang terlibat dalam self-injury memiliki alasan yang kompleks dan kadangkala sulit dimengerti sebagian orang, sehingga orang yang melakukan self-injury terlihat seperti orang yang aneh atau orang gila karena melukai dirinya secara sadar (Mounty, 2005). Meskipun tidak seluruhnya, kebanyakan pelaku self-injury mengalami penyiksaan di masa lalunya, baik secara fisik, emosional, maupun seksual, sehingga pada umumnya kurang mampu mengendalikan emosinya dan cenderung menghadapi banyak masalah di kemudian hari (Conterio, dalam Mounty, 2005). Menurut Walsh (1998), para pelaku cenderung melakukan self-injury adalah untuk meringankan emosi terlalu banyak

\section{Metode}

Pelaku self-injury bersifat subjek dimana alasan dari pelaku berbeda-beda, alasan terjadinya self-injury juga secara subjektif. Oleh karena itu penelitian ini menggunakan pendekatan kualitatif. Menurut Poerwandari (2005) pendekatan kualitatif sesuai digunakan untuk memahami manusia dalam segala kompleksitasnya sebagai makhluk subjektif, serta hal-hal yang membutuhkan pemahaman yang mendalam. 


\begin{abstract}
Metode penelitian kualitatif yang digunakan dalam penelitian ini menggunakan penelitian studi kasus. Penelitian studi kasus bertujuan untuk mempertahankan keutuhan (wholesness) dari objek penelitian, dalam arti objek dipelajari sebagai suatu keseluruhan yang terintegrasi.
\end{abstract}

Penelitian ini memilih dua subjek penelitian dan dua orang significant person yakni salah satu anggota keluarga dan teman dekat subjek. Penelitian ini menggunakan pengambilan sample kasus tipikal yaitu kasus yang dipilih adalah yang mewakili kelompok dari fenomena yang diteliti.

Sumber data pada penelitian ini yaitu pelaku self-injury nonsuicidal. Data yang digunakan dari penelitian ini yaitu berupa catatan wawancara, dan observasi.

Observasi dalam penelitian ini berguna untuk membantu peneliti dalam melihat reaksi dan observasi merupakan metode pengumpulan data yang essensial dalam penelitian, kegiatan memperhatikan secara akurat, dengan mencatat fenomena yang muncul dan mempertimbangkan hubungan dengan subjek penelitian (Purwandari, 2005). Obeservasi yang digunakan dalam penelitian ini adalah nonpartisipatif dan di tuliskan secara naratif, yaitu observer tidak ikuut melakukan apa yang dilakukan oleh subjek penelitian.

\section{Hasil dan Diskusi}

Mounty (2005) mengatakan bahwa pola asuh orang tua berperan penting bagi awal mula terjadinya pembentukan perilaku self-injury, karena ketahanan seorang anak didasarkan dari penerapan dia dengan situasi di dalam keluarganya. Dalam penelitian ini subjek (AL), tidak mendapatkan perhatian dan bimbingan dari orang tuanya sejak kecil. Sedari kecil subjek teloah di bebaskan oleh kedua orang tua subjek. peran orang tua dalam keluarga subjek tidaklah berjalan normal. Subjek (LT) sedari kecil
Bentuk wawancara yang digunakan dalam penelitian ini adalah Wawancara dengan pedoman umum, dalam proses ini peneliti dilengkapi pedoman wawancara yang sangat umum, yang mencatumkan isuisu yang harus diliput tanpa menentukan urutan pertanyaan, bahkan mungkin tanpa berbentuk pertanyaan eksplisit. Pedoman ini digunakan untuk mengingatkan peneliti mengenai aspek-aspek yang harus di bahas, sekaligus menjadi daftar pengecek (checklist) apakah aspek-aspek tersebut relevan tersebut akan dijabarkan atau ditanyakan. Wawancara adalah percakapan dan tanya jawab yang diarahkan untuk mecapai tujuan tertentu (poerwandari, 2002). Pada penelitian ini peneliti menggunakan pedoman wawancara untuk mengurangi penyimpangan dari tujuan penelitian, membantu mengarahkan peneliti mengenai aspek-aspek yang perlu di gali dari subjek.

Dalam hal ini peneliti melakukan triangulasi sumber data dan triangulasi metode. Triangulasi sumberdata yaitu mengambil data dari subjek penelitian dan dari orang-orang terdekat subjek. Triangulasi metode yaitu mengambil data dengan wawancara, catatan lapangan, dan dokumentasi. mendapatkan perhatian yang penuh kepada subjek. ayah dan ibu subjek selalu memberikan perhatian yang penuh kepada anak-anaknya. Subjek tidak pernah kekurangan kasih sayang. Namun, sikap ayah yang otoriter membuat subjek ingin merasa bebas.

Dari subjek yang diteliti memang peran pola asuh dalam keluarga sangat berperan sekali bagi perkembangan kepribadian seseorang. Pembentukan perilaku self-injury dirasakan subjek karena 
pera pola asuh orang tua subjek (AL) yang kurang cukup berperan. Serta peran pola asuh orang tua yang cenderung protective membuat subjek ingin merasakan kebebasan.

Menurut Hurlock (1980), pada umumnya sikap anak kepada orang tua berbeda-beda dan kehidupan secara keseluruhan berpola pada kehidupan rumah. Meskipun tidak satupun pola pendidikan anak yang dapat menjamin kesesuaian yang baik atau penyesuaian yang buruk, baik pribadi maupun sosial, ada bukti yang menunjukan bahwa anak dibesarkan dalam suasana rumah yang demokratis umumnya mempunyai penyesuaian diri yang lebih baik di bandingkan seorang anak yang dibesarkan secara otoriter.

Peran orang tua berbeda pada subjek penelitian ini. subjek (AL) tidak sama sekali mendapatkan peran orang tua yang baik baginya. Sedangkan subjek (LT) peran orang tua sangant baik berjalan di dalam keluarganya. Sehingga dapat disimpulkan bahwa peran orang tua belum tentu selalu merupakan alasan seseorang dalam melakukan self-injury ini. peran orang tua memang penting namun bagaimana seorang anak menerimanya itu adalah sebuah proses pembentukan kepribadian.

Kebanyakan pelaku self-Injury mengalami penyiksaan di masa lalunya, baik secara fisik, emosional, maupun seksual, sehingga pada umumnya kurang mampu mengendalikan emosinya dan cenderung menghadapi banyak masalah di kemudian hari (Conterio, dalam Mounty, 2005).

Peristiwa yang terjadi dimasa lalu membangun emosional tersendiri bagi subjek (AL) ia selalu terbayang-bayang oleh peristiwa pertengkaran orang tua subjek. Peristiwa tersebut terasa sangat membekas bagi subjek ia tidak mengira bahwa pertengkaran orang tuanya itu akan berakibat fatal baginya. Peristiwa itu menjadi pencetus subjek dalam melakukan pemutusan masalah-masalah selanjutnya. Subjek merasakan bahwa masalah-masalah ia tidak akkan pernah selesai. Subjek semakin tertekan karena subjek tidak pernah berbagi cerita kepada orang lain mengenai masalah-masalah yang datang kepadanya.

Kenangan masalalu yang tidak mengenakan juga dialami oleh subjek LT. ia menjadi seseorang yang murung dan menghindar dari orang lain saat ibu subjek meninggal dunia. Subjek yang sangat dekat dari ibunya tersebut merasa kehilangan sosok seseorang yang paling menyayanginya. Kejadian lain mengaggu dirinya adalah kejadian saat subjek berhubungan dengan pacaranya. Saat itu subjek merasa sangat menyesali perbuatannya dan menjadi rendah diri. Sehingga dari situ tercetuslah luapan-luapan emosi yang tidak terkendali olehnya.

Self-Injury dilakukan sebagai pembebasan tekanan dalam tubuhnya. Para pelaku self-Injury merasakan tubuhnya tertekan dan merasakan ketegangan yang mengganggu kenyamanan dirinya. Pelaku self-Injuy berusaha membuang emosi negatifnya dengan melakukan self- injury. (Alderman, 2007).

Subjek (AL), yang sedari kecil tidak mendapatkan perhatian dan kasih sayang orang tuanya, tumbuh menjadi perempuan yang bebas dan tidak suka di atur-atur. Subjek melakukan segala sesuatunya sesuai dengan keinginan subjek tanpa memikirkan orang lain. Ini juga yang dilakukan subjek saat menghadapi sebuat masalah. Ia cenderung merepres masalah tersebut dan membiarkan msalah tanpa menyelesaikannya. Subjek tidak suka berbagi cerita kepada orang lain. Sehingga setiap masalah yang datang kepadanya menjadi sebuah beban tersendiri bagi subjek.

Lain halnya dengan subjek (LT) meskipun ia mengalami kejadian yang menggangu dirinya subjek masih dapat menerima dan menyiapkan diri sedangan segala resiko yang akan ia terima. Subjek yang di didik oleh orang tua subjek dengan baik menjadi semakin baik dalam menghadapai setiap masalah yang ia temui. Sifat subjek yang terbuka kepada orang lain juga menjadi salah satu alasan dia lebih siap menerima setiap masalah dengan baik. Kematangan umur subjek juga menjadi 
alasan subjek dalam penerimaan diri dari masalah yang datang kepadanya. Subjek saat menghadapi sebuah masalah ia akan bersegera untuk menyelesaikan masalhnya itu sesegera mungkin. Namun tekanantekanan dari liuar diri subjek menjadikan subjek terkadang tidak dapat mengontrol emosi-emosi yang ada dalam dirinya.

Jadi penerimaan diri dalam menghadapi setiap masalah memang berperan sangat penting sehingga, seseorang dapat dengan siap menerima konflik atau masalah yang datang kepadanya, dan ia dapat menyelesaikan masalahnya tersebut dengan cara yang baik. Kesiapan diri ini juga dibentuk dari lingkungan dan kematangan diri seseorang.

Alderman dan Connors (2000) mengatakan bahwa sesungguhnya self-injury merupakan suatu metode yang digunakan untuk mempertahankan hidup dan merupakan suatu coping terhadap keadaan emosional yang sulit, seperti kecemasan, stress, dan perasaan negatif lainnya.

Kedua subjek sepakat bahwa melakukan self-injury adalah salah satu bentuk coping yang mereka pilih untuk menyelesaikan masalah mereka. Sebagai bentuk pelepasan-pelepasan emosi yang tidak terkendali, penyaluran emosi yang baik yang subjek pilih.

Penelitian ini menggunakan batasan bahwa subjek yang di teliti adalah bukan seorang pengguna narkoba, berbadan sehat dan menyadari bahwa ia melakukan tindakan self-injury. batasan ini di gunakan agar dapat membatasi subjek agar tidak keluar dari konteks penelitian ini. Self-injury adalah perilaku dimana seseorang sengaja melukai tubuhnya sendiri bukan bertujuan untuk bunuh diri melainkan hanya untuk melampiaskan emosi-emosi yang menyakitkan. Hal ini yang juga dilakukan oleh para subjek.

Banyak yang melakukannya karena mekanisme ini bekerja dan bahkan dapat menyebabkan kecanduan, self-Injury hanya menyebabkan pembebasan yang bersifat sementara dan tidak mengatasi akar permasalahan sehingga seseorang yang pernah melakukannya akan memiliki kecenderungan untuk mengulanginya dengan peningkatan frekuensi. Self-injury para pelakunya lebih sering terjadi pada remaja dan orang dewasa muda dibandingkan dengan orang dewasa madya. Remaja dan orang dewasa muda sedang berada dalam masa transisi sehingga sering menimbulkan gejolak yang tidak dapat di batasi oleh dirinya sendiri.

Dinamika psikologis seseorang adalah suatu perjalanan hidup seseorang dari mulai ia dilahirkan sampai dengan ia saat ini. Melalui dinamika dapat dilihat dan dipaparkan berbagai macam peristiwa dan kejadian yang terjadi selama kehidupannya. Pertistiwa-peristiwa tersebut merupakan kejadian masalalu yang dapat selalu dikenang dan membekas dalam diri seseorang. Begitu pula yang dialami oleh pelaku self-injury ini. Tahapan-tahapan dalam hidup seorang pelaku self-injury adalah sebuah rentetan peristiwa penting dan sebagai latar belakang ia melakukan tindakan self-injury ini.

Penerimaan diri dalam menghadapi masalah atau kejadian peristiwa yang terjadi dalam kehidupan pelaku di masa lampau dipengaruhi oleh keinginan yang tidak dapat tersalurkan. Keinginan yang tidak tersalurkan inilah yang kemudian membentuk suatu tingkah laku yang selanjutnya dijadikan tempat untuk dapat melepaskan keinginan-keinginan yang tidak tersalurkan tersebut, seperti misalnya melukai dirinya sendiri dengan cara menyilet tangan, mencakar-cakar tubuhnya, melebamkan bagian tubuhnya. Pelaku selfinjury ini menikmati dan merasakan pelepasan keinginan dan emosi yang tidak tersalurkan dari masalahnya tersebut. 


\section{Analisis Psikopatologis Antar Subjek}

\begin{tabular}{|c|c|c|}
\hline Kategorisasi & Subjek 1 (AL) & Subjek 2 (LT) \\
\hline Childhood Event & 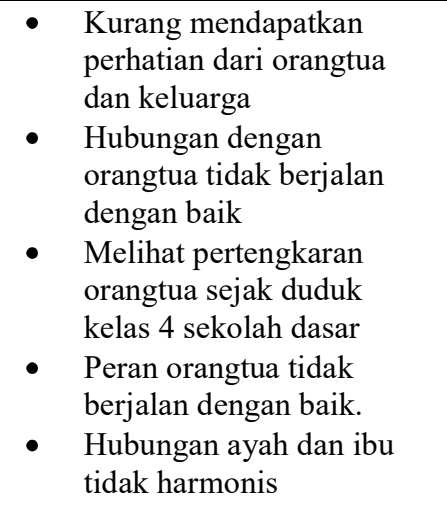 & 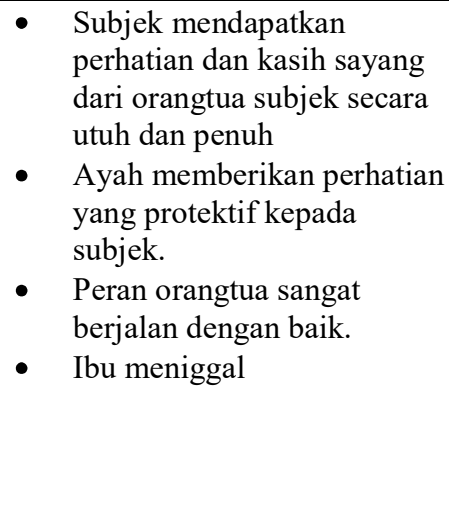 \\
\hline Later life & 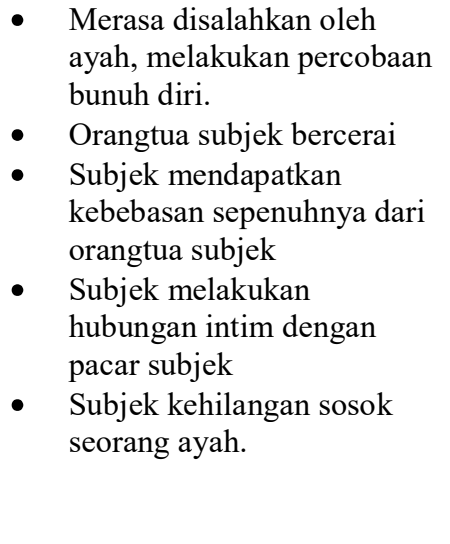 & 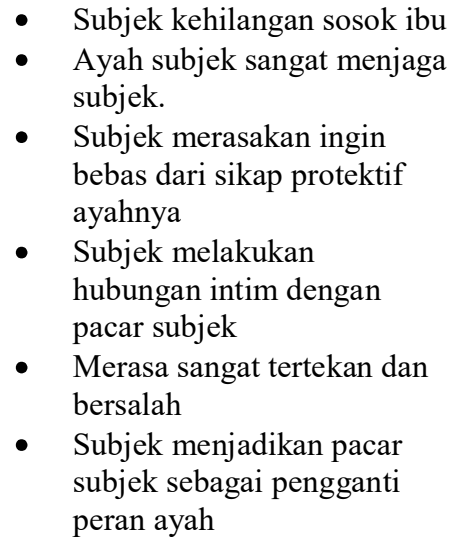 \\
\hline Conditioning event & $\begin{array}{l}\text { Kecewa terhadap sikap } \\
\text { orangtua } \\
\text { - } \quad \text { Ayah yang tidak berperan } \\
\text { baik dalam keluarga } \\
\text { - } \quad \text { Kecewa terhadap keluarga } \\
\text { yang tidak harmonis }\end{array}$ & $\begin{array}{l}\text { - } \\
\text { Sikap ayah yang terlalu } \\
\text { protektif } \\
\text { - Perasaan kehilangan sosok } \\
\text { ibu } \\
\text { - } \\
\text { Pembatasan yang di berikan } \\
\text { ayah }\end{array}$ \\
\hline Precipitating event & $\begin{array}{l}\text { - Orangtua yang sering } \\
\text { bertengkar } \\
\text { - } \quad \text { Subjek yang merasa selalu } \\
\text { disalahkan oleh ayah }\end{array}$ & $\begin{array}{l}\text { Pertengkaran dengan pacar } \\
\text { subjek }\end{array}$ \\
\hline Complex & $\begin{array}{l}\text { Tidak diperhatikan oleh } \\
\text { orangtua } \\
\text { - } \quad \text { Peran keluarga yang tidak } \\
\text { baik } \\
\text { - } \quad \text { Selalu memendam } \\
\text { masalah } \\
\text { - } \quad \begin{array}{l}\text { Putus cinta dan hubungan } \\
\text { dengan pacar tidak baik }\end{array}\end{array}$ & $\begin{array}{l}\text { - } \quad \text { Perhatian yang berlebihan } \\
\text { dari orangtua } \\
\text { - } \quad \text { Sikap ayah yang protektif } \\
\text { - } \quad \text { Memendam masalah }\end{array}$ \\
\hline Self-injury behavior & $\begin{array}{ll}\text { - } & \text { Intensitas subjek } \\
\text { melakukan self-injury } \\
\text { sering } \\
\text { Self-injury dilakukan } \\
\text { subjek dengan }\end{array}$ & $\begin{array}{ll}\text { - } & \text { Intensitas subjek melakukan } \\
\text { - } & \text { Self-injury tidak sering. } \\
& \text { Self-Injury subjek dilakukan } \\
\text { dengan menggunakan silet } \\
\text { - } \quad \text { Subjek merasa lebih baik }\end{array}$ \\
\hline
\end{tabular}




\begin{tabular}{|c|c|c|}
\hline Simptom & $\begin{array}{l}\text { menggunakan silet } \\
\text { - } \\
\text { Subjek merasa tenang saat } \\
\text { setelah melakukan self- } \\
\text { injury } \\
\text { - } \quad \text { Subjek melakukan self- } \\
\text { injury sebagai pelepasan } \\
\text { emosi-emosi subjek. } \\
\text { - } \\
\text { Awal mula melakukan } \\
\text { self-injury karena melihat } \\
\text { orangtua subjek } \\
\text { bertengkar } \\
\text { - } \text { Gelisah } \\
\text { - Cemas } \\
\text { - } \quad \text { Rendah diri } \\
\text { Melukai diri }\end{array}$ & $\begin{array}{l}\text { ketika melakukan self-injury } \\
\text { - Subjek melakukan self- } \\
\text { injury sebagai emosi subjek } \\
\text { tidak tersalurkan } \\
\text { - Self-injury dilakukan subjek } \\
\text { karena subjek merasa cemas } \\
\text { sehabis melakukan } \\
\text { hubungan dengan pacar } \\
\text { subjek }\end{array}$ \\
\hline
\end{tabular}

\section{Kesimpulan}

Self-injury dalam penelitian ini dilakukan oleh wanita. Secara keseluruhan subjek ini cenderung melakukan self-injury untuk membantunya mengalihkan emosi yang ia rasakan dan berusaha menghindari masalahnya. Meskipun cara penyampaian dan penyelesaian masalah mereka berbeda, namun mereka cenderung tidak menyampaikan setiap masalah pada orang yang bersangkutan dan sebagai bentuk refleksi dari masalah yang ditimbulkan oleh orang lain kepada diri subjek. Mereka lebih melakukan self-injury sebagai cara penyelesaian mereka. Subjek cenderung memendam masalahnya dan membiarkan masalahnya tidak terselesaikan. Pengasuhan dan pengajaran yang di terapkan di dalam keluarga cukup berperan bagi subjek sebagai pemicu perilaku self-injury ini.

Subjek AL melakukan self-injury di dasari oleh faktor keluarga. Pola asuh yang diterapkan di dalam keluarga AL tidaklah baik. Peran masing-masing anggota keluarga tidak berjalan sebagaimana mestinya. Sikap orang tua yang kasar dan tidak memberikan contoh yang baik kepada subjek. keadaan orang tua yang tidak baik inilah yang membuat subjek melakukan self-injury. Kurangnya perhatian dan kasih sayang dari orang tua membuat subjek melakukan tindakan-tindakan yang tidak terkontrol olehnya seperti melakukan self-injury. Subjek merupakan orang yang tertutup sehingga ia sering sekali merepress masalahnya, sehingga penerimaan diri terhadap masalahnya kurang baik bagi subjek. ia cenderung menghindar dari masalah dan membiarkan masalah tidak terselesaikan. Tumbuh dengan tanpa arahan dari orang tua membuat subjek mengikuti pergaulan bebas, sehingga apabila menerima suatu konflik ia melakukan coping dengan cara yang tidak baik yang menghawatirkan dirinya sendiri serta orang lain.

Subjek LT didapatkan hasil bahwa peran keluarga cukup berpengaruh banginya. Pola asuh yang di terapkan oleh keluarga subjek sangatlah baik, namun sikap ayah yang terlalu protective membuat subjek sering sekali ingin merasakan bebas. Perasaan-perasaan ingin bebas inilah yang mendorong subjek untuk mencoba hal-hal baru dalam hidpunya, sampai ia tidak dapat mengontrol tingkahlakunya dan melakukan sebuah hubungan dengan lelaki teman dekatnya. Peristiwa ini menjadikan subjek merasa bersalah dan tertekan. Rasa tersebutlah yang menjadikan subjek melakukan coping masalah yang tidak baik dengan melakukan self-injury. Subjek bukanlah merupakan orang yang tertutup ia berbagi cerita kepada orang-orang terdekatnya, namun subjek kurang dapat mengontrol emosi-emosi dari konflikkonflik yang ia hadapi. Hal inilah yang menjadikan subjek melakukan self-injury sebagai coping dan pelepasan masalah yang ia rasakan. 
Terjadinya perilaku self-injury bergantung pada keadaan emosional, sehinga setiap subjek berbeda durasi dan kelangsungan perilaku self-injury nya.

\section{Daftar Pustaka}

Alderman, T. (1997). The scarred soul: Understanding \& ending self-inflicted violence. Oakland, CA : New Harbinger.

Barent W. Walsh, (2006) Treating Self-Injuri: A Practical Guide. New York: Guilford Press.

Connors, R. E. (2000). Self-Injuri: psychotherapy with people who engage in self-inflicted violence. Northvale, NJ: Jakson Aronson Inc.

Creswell. Jhon. W., (2010). research desain (qualitative, quaititative, and mixed method approaches. Third Edition. Jakarta: pustaka pelajar

Favazza.A.R. (1987). Bodies Under Siege: Self-Mutilation in Culture and Psychiatry. Baltimore: Johns Hopkins University Press

Favazza. A., Conterio. K., (1989). Female habitual self-mutilators. Acta Psychiatrica Scandinavica79:283-289

Favazza, A. R. (1996). Bodies under siege: self-mutilation and body modification in culture and psychiatry $\left(2^{\text {nd }}\right.$ edition). CA: Jhons Hopkins University Press.

Favazza, A. R. (1996). Bodies under siege: Self-mutilation and body modification in culture and psychiatry. London: The John Hopkins University Press.

Hilt.L.M., Cha.C.B., Nolen.Hoeksema.C. (2008). Nonsuicidal self-Injuri in young adolescent girls: Moderators of the distress-function relationship. J.Consult Clin Psychol

Hulock. Elizabeth. (1980). Psikologi Perkembangan edisi kelima terjemahan. Jakarta: Penerbit erlangga subjek. Penerimaan diri dalam penyelesaian masalah seseorang menjadi salah satu faktor dalam terjadinya perilaku self-injury.

Hyman.J. (1999). Women Living With Self-Injuri. Philadelphia: Temple University Press.

Ilmi, Rizqi. T, M. (2011). Pengaruh kematangan emosi terhadap kecenderungan perilaku self-injury pada remaja. Skripsi (tidak diterbitkan). Universitas Islam Syarif Hidayatullah Jakarta.

Kettlewell. C. (1999). Skin Game: A Cutter's Memoir. New York: St Martin's

Klonsky, E. D., Muehlenkemp, J. J (2007). Self injury: A research review for the practioner. Wiley interscience.

Klonsky, E. D., Oltmanns, T. F., \& Turkheimer, E. (2003). Deliberate self-harm in a nonclinical population: Prevalence and psychological correlates. The American Journal of Psychiatry,

Levenkron.S. (1998). Cutting: Understanding and Overcoming SelfMutilation. New York: Norton.

Mazelis, R. (2008). Self-Injuri: understanding and responding to people who live whit self-inflicted violence. California : national center for traumainformed care.

Muehlenkamp.et al. (2012). Child and Adolescent Psychiatry and Mental Health.

http://www.capmh.com/content/6/1/12 6:10

Muehlenkamp. J. J. (2007). Gutierrez PM: Risk for suicide attempts among adolescents who engage in nonsuicidal self-Injuri. Arch Suicide Res

Monty. P. S., Tresno. F. ( 2005). Dinamika emosional pelaku self-Injuri, Jakarta: Universitas Taruma Negara. 
Patton GC, and all. (2007). Pubertal stage and deliberate self-harm in adolescents. J.Am Acad Child Adolesc Psychiatry

Pegerl, Naomi, L. (2010). A comparison of the fuction or eating disorder behaviors to non-suicidal self-injury. Disertation and These. Universiti of north Dakota.

Spigner, C., Shigaki, A., \& Tu, S. P. (2005). Perceptions of Asian American men about tobacco cigarette consumption: A social learning theory framework. Journal of Immigrant Health.

Stanley, B., Winchel, R. M., Molcho, A., Simeon, D., \& Stanley, M. (1992). Suicide and the self-harm continuum: Phenomenological and biochemical evidence. International Review of Psychiatry.

Stein, D., Lilenfield, L. R. R., Wildman, P. C., \& Marcus, M. (2004). Attempted suicide and self-Injuri in patients diagnosed with eating disorders. Comprehensive Psychiatry.

Strong.M. A., Bright. (1998). Red Scream: Self-Mutilation and the Language of Pain. New York: Viking

Sugiyono. (2009). Metode penelitian kuantitaif, kualitatif, dan $R \& D$. Cetakan ke Jakarta: cv. Alfabeta

Supardi, Sawitri. (1982). Paradigma Psikopatologi. Bandung: biro psikologi psikodinamika

Turner, V. J. (2002). Secret scars: Unconvering, and Understanding the addiction of self-injry. Center city, $\mathrm{MN}$ : Hazelden

Walsh. B, Rosen P (1988). Self-

Mutilation: Theory, Research, and Treatment. New York: Guilford 